\title{
Properties of the Lectin from the Hog Peanut (Amphicarpaea bracteata) ${ }^{1}$
}

\author{
MARY J. MALIARIK, DAVID D. ROBERTS, ${ }^{2}$ AND IRWIN J. GOLDSTEIN ${ }^{3}$
}

Department of Biological Chemistry, University of Michigan Medical School, Ann Arbor, Michigan 48109

Received December 19, 1986

An $N$-acetyl-D-galactosamine-specific lectin has been isolated from the two seed forms of the hog peanut (Amphicarpaea bracteata) using an affinity support containing the synthetic type A blood group trisaccharide $\alpha-\mathrm{D}-\mathrm{GalNAc}-(1,3)-[\alpha-\mathrm{L}-\mathrm{Fuc}-(1,2)]-\beta-\mathrm{D}-\mathrm{Gal}$ (Synsorb A). The affinity-purified lectin appears to be identical in both seed types. Gel filtration on Sephadex G-200 gives a single symmetrical peak corresponding to $M_{\mathrm{r}} 135,000$. Sodium dodecyl sulfate-polyacrylamide gel electrophoresis shows four subunit forms, each of which contains carbohydrate. Limited amino terminal sequencing indicates heterogeneity in two of the first 10 residues. The lectin contains no cysteine. There are four equivalent, noninteracting GalNAc binding sites per 135,000-Da molecule, having an association constant for methyl $N$-acetyl- $\alpha$-D-galactosaminide of $4.0 \times 10^{4} \mathrm{M}^{-1}$. Precipitin and hapten inhibition studies show the lectin to be specific for terminal, nonreducing $D$-GalNAc units, with a preference for the $\alpha$-anomer and enhanced specificity for the disaccharide, GalNAc $\alpha 1,3 \mathrm{GalNAc}$. There is also a single adenine binding site per $M_{\mathrm{r}}$ 135,000 lectin molecule with an association constant of $1.3 \times 10^{6} \mathrm{M}^{-1}$. 01987 Academic Press, Inc.

The anti-A lectin from Amphicarpaea bracteata (hog peanut) seeds (1) is one of several Leguminoseae lectins specific for terminal nonreducing $\mathrm{D}-\mathrm{GalNAc^{4 }}$ groups. The genus Amphicarpaea contains two seed types: one above ground and one which develops at the base of the stem, near or below the soil surface. The lectin was first isolated from the conventional aerial seeds by Blacik and co-workers (2) by affinity

${ }^{1}$ This research was supported in part by Grant GM 29470 from the U.S. Public Health Service.

${ }^{2}$ Current address: Laboratory of Structural Biology, Building 8A, Room 2A25, Bethesda, MD 20892.

${ }^{3}$ To whom correspondence should be addressed: Department of Biological Chemistry, University of Michigan Medical School, 1301 Catherine Rd., Ann Arbor, MI 48109-0606.

${ }^{4}$ Abbreviations used: $\mathrm{Me} \alpha$ - and Me $\beta$-D-GalNAc, methyl $N$-acetyl- $\alpha$ - and methyl $N$-acetyl- $\beta$-D-galactosaminide, respectively; $p-\mathrm{NO}_{2}$ phe, para nitrophenyl; D-Gal, D-galactopyranose; L-Fuc, L-fucose; PBS, phosphate-buffered saline $(0.1 \mathrm{M} \mathrm{Na}$ phosphate, $0.15 \mathrm{M}$ $\mathrm{NaCl}, \mathrm{pH} 6.8,0.1 \mathrm{~mm} \mathrm{MnCl}, \mathrm{MgCl}_{2}$, and $\mathrm{CaCl}_{2}$ ); SDSPAGE, sodium dodecyl sulfate-polyacrylamide gel electrophoresis; GlcNAc, $N$-acetyl-D-glucosamine. chromatography on a matrix prepared by coupling $N$-acetyl-D-galactosamine to expoxy-Sepharose 6B. The purified lectin was reported to be homogeneous by SDS-polyacrylamide gel electrophoresis. Inhibition of hemagglutination established the carbohydrate binding specificity to be $\mathrm{D}$ GalNAc $>\alpha-\mathrm{D}-\mathrm{Gal}>\beta$-D-Gal.

We report here purification of the lectin from $A$. bracteata from both types of seeds and further characterization of its physical and chemical properties.

\section{MATERIALS AND METHODS}

Isolation of lectin. A. bracteata seeds were collected in New Hampshire and from the Matthei Botanical Gardens of the University of Michigan. A crude extract of $A$. bracteata seeds was prepared using a modified procedure of Blacik et al. (2). Ground dried seeds were delipidated by two extractions with methanol $(1 / 10, w / v)$, washed with dichloromethane, and airdried. The material was extracted twice with PBS at $4^{\circ} \mathrm{C}$. The combined extracts were applied to an affinity column of high capacity Synsorb A (Chembiomed, Alberta, Canada) which contained the synthetic blood group A trisaccharide, $\alpha$-D-GalNAc- $(1,3)-[\alpha-D-F u c-$ 
$(1,2)]-\beta$-D-Gal-Synsorb. Alternatively, GalNAc-BioGlas 1000 (Chembiomed) may be used as an affinity support. The column was washed extensively with PBS to remove unbound protein. The lectin was eluted with 0.1 м $N$-acetyl-D-galactosamine (Pfanstiehl, Waukegan, IL) in PBS and dialyzed against PBS. A final wash with $0.1 \mathrm{M}$ acetic acid, $\mathrm{pH}$ 3.0, removed a small amount of material which absorbed at $280 \mathrm{~nm}$ but did not stain for protein on gel electrophoresis. Lectin concentrations were determined by Lowry assay (3) using bovine serum albumin as standard. Lectin activity was assayed by hemagglutination of a $2 \%$ (v/ v) suspension of human type A red blood cells, with specific titer $\left(\mathrm{mg}^{-1} \mathrm{ml}\right)$ expressed as reciprocal of the maximum serial dilution giving agglutination from a $1 \mathrm{mg} \mathrm{ml}^{-1}$ solution.

Electrophoretic techniques. Polyacrylamide gel electrophoresis at $\mathrm{pH} 8.9$ was run as described (4). Polyacrylamide gel electrophoresis in the presence of SDS was performed in $12 \%$ acrylamide gels according to Laemmli (5). Molecular weights were estimated using bovine serum albumin, ovalbumin, chymotrypsinogen $\mathrm{A}$, ribonuclease, and cytochrome $c$ as standards. Isoelectric focusing in the presence of $8 \mathrm{M}$ urea was conducted as described (6) using Biolytes 4/6 and 3/10 (Bio-Rad, Richmond, CA). Gels were assayed for the presence of carbohydrates using the thymol-sulfuric acid stain (7).

Gel filtration. Analytical gel filtration was performed using a column $(1.5 \times 115 \mathrm{~cm})$ of Sephadex G200 superfine (Pharmacia, Piscataway, NJ) in PBS. The column was calibrated using human gamma globulin, bovine serum albumin, ribonuclease, and cytochrome $c$.

Sugars and derivatives. Preparation of methyl 2acetamido-2-deoxy- $\alpha$ - and $\beta$-D-galactopyranosides and $p$-azophenyl- $\beta$-D-GalNAc-bovine serum albumin conjugate has been described (8). Methyl 2-O-acetyl$\alpha$-D-galactopyranoside and methyl $2-N$-benzamido-2deoxy- $\alpha$-D-galactopyranoside were prepared by Dr. $R$. Kaifu as described (9). The disaccharides $\alpha-\mathrm{D}-\mathrm{GalNAc}-$ (1,3)-D-Gal, $\alpha$-D-GalNAc-(1,6)-D-Gal, and $\beta$-D-GalNAc-(1,6)-D-Gal were synthesized by N. Plessas of this laboratory. Additional sugars were from Pfanstiehl Laboratory (Waukegan, IL).

Quantitative precipitation inhibition assay. The carbohydrate binding specificity of the lectin was determined by a precipitin inhibition assay as described (10). Lectin $(16 \mu \mathrm{g})$ was mixed with hog $\mathrm{A}+\mathrm{H}$ gastric mucin $(10 \mu \mathrm{g})$ to which varying concentrations of haptenic sugars were added in a final volume of 0.2 ml. After incubation at $25^{\circ} \mathrm{C}$ for $48 \mathrm{~h}$, the tubes were centrifuged and the precipitates were washed with PBS $(0.4 \mathrm{ml})$. The washing procedure was repeated twice. The precipitates were dissolved by addition of $0.1 \mathrm{ml} 0.5 \mathrm{M} \mathrm{NaOH}$ and, after standing for $1 \mathrm{~h}$, protein was determined by a micro Lowry assay (11).

Equilibrium dialysis. Binding of $\left[{ }^{14} \mathrm{C}\right]$ methyl $N$-ace- tyl- $\alpha$-D-galactosaminide and $\left[{ }^{14} \mathrm{C}\right]$ adenine (New England Nuclear, Boston, MA) were determined in microdialysis cells (Technilab Instruments, Inc., Pequannock, NJ) using $0.3-\mathrm{ml}$ volumes of lectin and ligand in PBS. Following equilibration at $4^{\circ} \mathrm{C}$, the concentration of $\left[{ }^{14} \mathrm{C}\right]$ methyl $\alpha$-D-GalNAc in each chamber was determined by scintillation counting of duplicate aliquots.

Amino terminal sequence analysis was performed by the University of Michigan Protein Sequencing Facility using manual Edman degradation (12). Amino acid analyses were done by HPLC analyses of phenylthiocarbamyl amino acids (13). Cysteine was determined as cysteic acid.

Carbohydrate analysis. High-performance liquid chromatography analysis of carbohydrates was performed by Dr. Fulvio Perini at the University of Michigan (14). Concanavalin A-Sepharose was purchased from Pharmacia.

\section{RESULTS}

Purification of the A. bracteata lectin. Application of the crude extract from $A$. bracteata to Synsorb A resulted in quantitative retention of hemagglutinating activity. The bound lectin was eluted with 0.1 M GalNAc (Fig. 1). Subsequent washing with $0.1 \mathrm{M}$ acetic acid eluted additional material which absorbed at $280 \mathrm{~nm}$. However, this material did not agglutinate type A erythrocytes; nor did it stain for protein on SDS-gel electrophoresis.

Yields of lectin varied from 100 to $800 \mu \mathrm{g}$ per gram of seeds, depending upon the source. The subterranean seeds gave slightly higher yields than the aerial seeds.

Physical-chemical properties of the lectin. Affinity purified lectin gave a single sym-

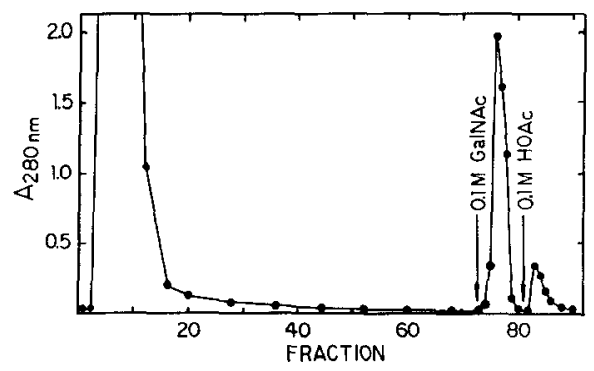

FIG. 1. Affinity purification of $A$. bracteata lectin on Synsorb A. Lectin in PBS was applied to the column, washed with PBS until the absorbance was less than 0.03, then eluted with $0.1 \mathrm{M}$ GalNAc in PBS. 
metrical peak upon gel filtration with $M_{\mathrm{r}}$ 135,000 (Fig. 2). After extensive dialysis against distilled water, the lectin was lyophilized and dried to constant weight in vacuo at $100^{\circ} \mathrm{C}$. The protein was dissolved in PBS and the absorbance at $280 \mathrm{~nm}$ was recorded. An extinction coefficient was determined to be $13.6 E_{280}^{1 \%}$. A single diffuse band was obtained upon polyacrylamide gel electrophoresis at $\mathrm{pH} 8.9$ (Fig. 3B). SDSPAGE showed four bands of $M_{\mathrm{r}} 32,000$, $30,000,28,000$, and 27,500 (Fig. $3 \mathrm{~A}$ ). Incubation of the lectin with $\beta$-mercaptoethanol did not alter the profile. Isoelectric focusing in $8 \mathrm{M}$ urea resulted in several bands with apparent $\mathrm{p} P \mathrm{~s}$ of $5.5-6.5$ (Fig. 3C). SDSPAGE of protein recovered from focused bands, however, revealed the presence of more than one subunit type. Thus part of the charge heterogeneity seen upon isoelectric focusing may be an artifact due to incomplete dissociation in $8 \mathrm{M}$ urea.

Staining of SDS gels with thymol-sulfuric acid indicated that all the lectin bands contained carbohydrate. Carbohydrate analysis showed the lectin to be a glycoprotein containing $4 \%$ carbohydrate by weight, consisting of glucosamine, mannose, galactose, fucose, arabinose, and xylose residues in the molar ratio 4:3:2:1:2:2. The lectin was quantitatively retained on

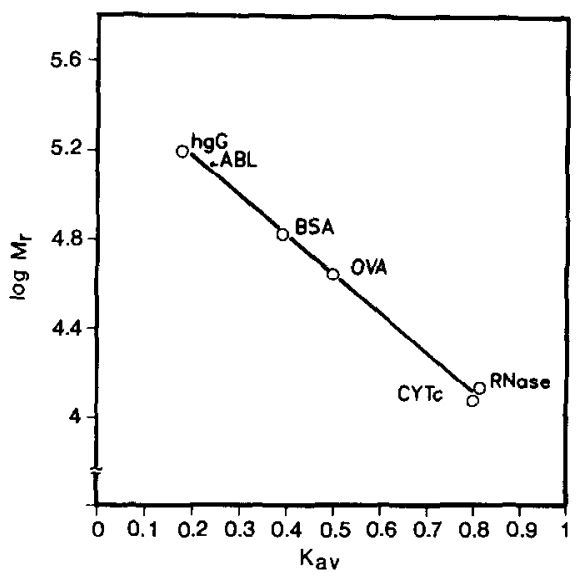

Fig. 2. Gel filtration of $A$. bracteata lectin (ABL). Molecular weight markers used were human gamma globulin (hgG, $M_{\mathrm{r}}$ 153,000); bovine serum albumin (BSA, $M_{\mathrm{r}} 68,000$ ); ovalbumin (OVA, $M_{\mathrm{r}} 43,000$ ); RNase $\left(M_{r} 13,800\right)$; and cytochrome $c\left(\right.$ CYTc $\left.M_{r} 12,700\right)$.

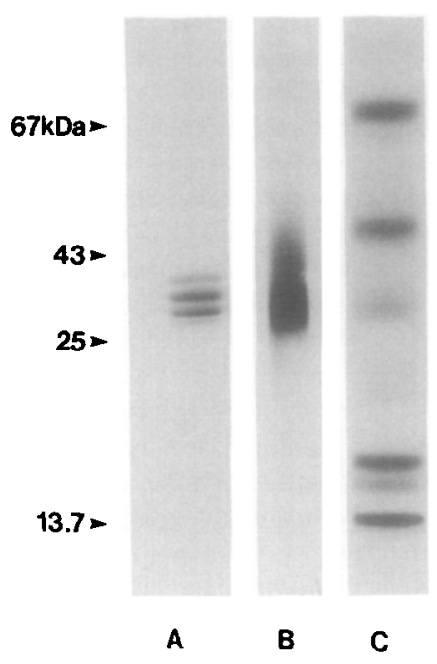

FIG. 3. Polyacrylamide gel electrophoresis of $A$. bracteata lectin. (A) pH 8.9 PAGE; (B) SDS-PAGE; (C) isoclectrofocusing of lectin in $8 \mathrm{M}$ urea.

a concanavalin A-Sepharose column and was eluted by $0.1 \mathrm{M}$ methyl $\alpha$-D-mannopyranoside confirming the presence of mannose-terminated and/or 2-O- $\alpha$-Dmannopyranosyl-containing oligosaccharide chains.

Amino acid analysis data for $A$. bracteata lectin are shown in Table I. Amino acid composition was computed on a mol/1000 mol basis and was compared to the data from Blacik et al. (2). The present data are in agreement with the previous work, in that the lectin is rich in serine, leucine, aspartic acid, and glutamic acid. However, some notable differences were found. The content of histidine was much lower than previously reported, and the amount of methionine found by this laboratory was only 1 residue/ 1000 mol versus 18.8 residues $/ 1000 \mathrm{~mol}$ found earlier. Cysteine was absent.

Amino terminal sequence data for the A. bracteata lectin are shown in Fig. 4. Equal amounts of serine and threonine along with smaller quantities of glycine, alanine, and aspartic acid were released on the first cycle of degradation. Subsequent cycles gave one predominant residue, except the fifth cycle, which released equimolar amounts of serine and proline.

Carbohydrate binding specificity. Equilibrium dialysis using $\left[{ }^{14} \mathrm{C}\right]$ methyl $N$-ace- 


\section{TABLE I}

Amino ACID ANAlysis Of THE LECTIN FROM Amphicarpaea bracteata

\begin{tabular}{lcc}
\hline & \multicolumn{2}{c}{ Residues $\mathbf{1 0 0 0} \mathbf{m o l}$} \\
\cline { 2 - 3 } $\begin{array}{c}\text { Amino acid } \\
\text { residue }\end{array}$ & $\begin{array}{c}\text { New Hamphire } \\
\text { seeds }\end{array}$ & $\begin{array}{c}\text { Illinois } \\
\text { seeds }^{a}\end{array}$ \\
\hline Asp & 121 & 113 \\
Thr & 74 & 60.7 \\
Ser & 132 & 139 \\
Glu & 77 & 129 \\
Pro & 40 & 39.5 \\
Gly & 105 & 114 \\
Ala & 75 & 88.3 \\
Val & 75 & 31.3 \\
Met & 1 & 18.8 \\
Ile & 54 & 38.5 \\
Leu & 96 & 75.8 \\
Tyr & 28 & 13.3 \\
Phe & 52 & 35.1 \\
His & 15 & 47.1 \\
Lys & 43 & 44.5 \\
Arg & 13.0 & 12.0 \\
Cys & 0 & -6 \\
\hline
\end{tabular}

${ }^{a}$ Data taken from Blacik et al. (2).

${ }^{b}$ Not available.

tyl- $\alpha$-D-galactosaminide as binding ligand indicated four equivalent, noninteracting sugar binding sites per molecule $\left(M_{r}\right.$ 135,000 ), with $K_{a}=4.0 \times 10^{4} \mathrm{M}^{-1}$ (Fig. 5). A strong precipitin reaction was observed upon mixing $A$. bracteata lectin with hog mucin $\mathrm{A}+\mathrm{H}$ substance. Weak precipitin reactions were also observed with type $A$ blood group substance and $p$-azophenyl- $\beta$ GalNAc-bovine serum albumin conjugate. No reaction was detected with guaran or bovine submaxillary mucin. A precipitin curve of $A$. bracteata lectin with hog $\mathrm{A}+\mathrm{H}$ substance is shown in Fig. 6.
A. BRACTEATA
(S) $\quad G \quad T \quad V(\underset{S}{F})$ F
G. MAX
A E T V S F S W N K
D. BLELORUS
A N T Q S S F S F Q N

Fig. 4. Comparison of $N$-terminal sequence of the lectin from A. bracteata with those from Glycine max and Dolichos biflomus.

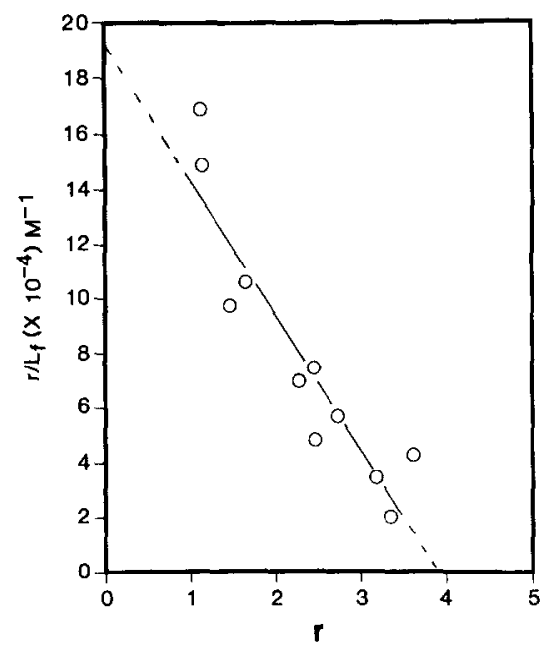

FIG. 5. Scatchard plot of the binding of $\left[{ }^{14} \mathrm{C}\right] \mathrm{GalNAc}$ to A. bracteata lectin. A. bracteata $(0.81 \mathrm{mg} / \mathrm{ml})$ and $\left[{ }^{14} \mathrm{C}\right] \mathrm{GalNAc}(30-500 \mu \mathrm{M})$ were rotated at $4^{\circ} \mathrm{C}$ for 48 h; 100- $\mu$ l samples were counted to determine the concentrations of bound and free ligand.

Inhibition of the precipitin reaction with hog $\mathrm{A}+\mathrm{H}$ substance was used to further characterize the carbohydrate binding specificity of the A. bracteata lectin. Results of precipitin inhibition studies are summarized in Table II. Except where noted all $50 \%$ inhibition values were determined from complete inhibition curves. $D$-GalNAc was found to be 50-fold more potent an inhibitor than $\mathrm{Me} \alpha \mathrm{Gal}$, which compares well with the 100-fold difference observed by the hapten inhibition of hemagglutination technique (2). There is also good agreement between the methods as to the relative potencies of lactose and GlcNAc. The $\alpha$ -

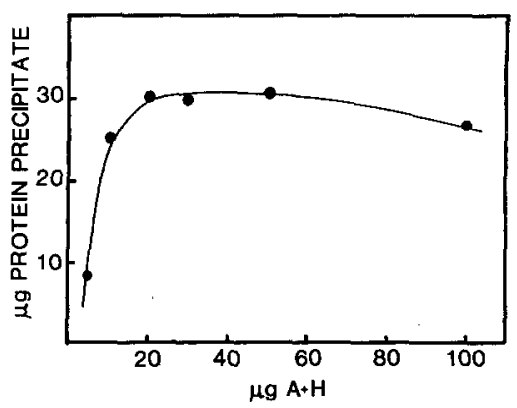

FIG. 6. Precipitation of $A$. bracteala lectin by hog A $+\mathrm{H}$ gastric mucin. 
TABLE II

Amphicarpaea bracteata LECTIN PRECIPITIN INHIBITION

\begin{tabular}{|c|c|}
\hline Sugar & $\mathrm{ID}_{50}(\mathrm{mM})$ \\
\hline$p$ - $\mathrm{NO}_{2} \mathrm{Phe} \alpha$ GalNAc & 0.15 \\
\hline (2-N-Benzamido)Me $\alpha$ GalN & 0.16 \\
\hline Me $\alpha$ GalNAc & 0.18 \\
\hline$p$ - $\mathrm{NO}_{2}$-Phe $\beta$ GalNAc & $0.30(63)^{b}$ \\
\hline Me2- $O$-Acetyl- $\alpha \mathrm{Gal}$ & 0.33 \\
\hline GalNAc & 0.46 \\
\hline $\mathrm{Me} \beta$-GalNAc & 0.77 \\
\hline Me $\alpha \mathrm{Gal}$ & 22 \\
\hline GlcNAc & $100 \quad(42)$ \\
\hline $1 a^{(a)}$ & 2.0 \\
\hline $1 b^{(a)}$ & 0.28 \\
\hline GalNAc $\alpha 1,3 \mathrm{GalNAc} \beta-O-\left(\mathrm{CH}_{2}\right)_{8} \mathrm{CO}_{2} \mathrm{Me}$ & 0.067 \\
\hline GalNAc $\alpha 1,2 \mathrm{Gal} \beta-\mathrm{O}-\left(\mathrm{CH}_{2}\right)_{8} \mathrm{CO}_{2} \mathrm{Me}$ & 0.15 \\
\hline GalNAc $\alpha 1,3 \mathrm{Gal}$ & 0.29 \\
\hline GalNAc $\beta 1,6 \mathrm{Gal}$ & 0.56 \\
\hline GalNAc $\alpha 1,6 \mathrm{Gal}$ & 0.59 \\
\hline Lactose & 15 \\
\hline Melibiose & 24 \\
\hline
\end{tabular}

${ }^{a} 1 \mathrm{a}$ is $1-[4(N$-acetyl- $\alpha$-D-galactosaminyl $)$ phenyl]-3(2,2,6,6-tetramethylpiperidin-1-oxyl-4-yl)-2-thiourea; Berliner, et al (19); $1 \mathrm{~b}$ is the $\beta$ anomer of $1 \mathrm{a}$.

${ }^{b}$ Numbers in parentheses give percentage inhibition at the concentration tested.

methyl glycoside of GalNAc was 4-fold more inhibitory than the $\beta$-methyl glycoside.

The $p$-nitrophenyl $\alpha$-glycoside of GalNAc was only slightly more potent than the $\beta$ anomeric derivative $(0.16 \mathrm{vs} 0.23 \mathrm{mM})$, but the $p$-nitrophenyl $\beta$-glycoside was four times more potent than the methyl $\beta$-glycoside, suggesting a possible interaction of the protein with the $\beta$ - $p$-nitrophenyl group. Modifications at the $\mathrm{C}-2$ position had little effect on binding to $A$. bracteata lectin. Replacing the amide nitrogen of $\mathrm{Me} \alpha$ GalNAc with oxygen (methyl 2-O-acetyl$\alpha$-D-galactopyranoside) decreased binding slightly.

Several disaccharides terminating in GalNAc were also studied. Of these, the Forssman disaccharide (GalNAc $\alpha$ l,3GalNAc) was the most inhibitory $\left(K_{\mathrm{I}}=0.067\right.$ $\mathrm{mm}$ ). Although the lectin is specific for terminal, nonreducing GalNAc residues, the nature of the glycosidic linkage also appears to have a significant effect on binding.
Specifically, $\alpha(1,2)$ and $\alpha(1,3)$ linkages are better inhibitors than disaccharides containing $\alpha(1,6)$ linkages.

This lectin was also found to bind adenine very tightly, with $K_{a}=1.3 \times 10^{6} \mathrm{M}^{-1}$ (Fig. 7). Equilibrium dialyses indicated a single adenine binding site per molecule of $M_{\mathrm{r}} 135,000$. This property puts the lectin in a class with several other legume lectins which have been observed to contain an adenine-specific binding site along with their carbohydrate binding site (21).

\section{DISCUSSION}

Synsorb $A$ is an effective affinity support for purification of the A. bracteata lectin. Yields vary from seeds collected in different locals, the New Hampshire seeds containing the most lectin.

Blacik and co-workers found the lectin to be homogeneous upon electrophoresis in SDS (2). An apparent molecular weight was not reported. Our results indicate that the lectin consists of multiple subunit forms, which differ in both size and charge. Subunit heterogeneity has also been reported for a number of other GalNAc binding lectins such as lima bean (6) and Dolichos biflorus (15). The behavior of the

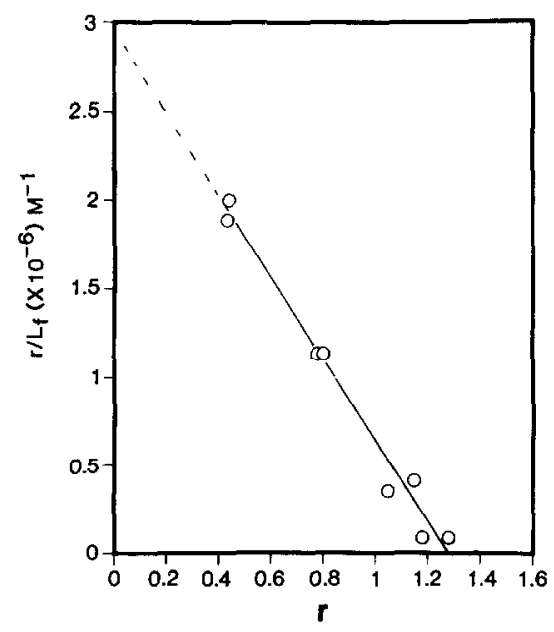

FIG. 7. Scatchard plot of binding of $\left[{ }^{14} \mathrm{C}\right]$ adenine to A. bracteata lectin. A. bracteata lectin $(1.0 \mathrm{mg} / \mathrm{ml})$ and $\left[{ }^{14} \mathrm{C}\right]$ adenine $(5-400 \mu \mathrm{M})$ were rotated at $25^{\circ} \mathrm{C}$ for $24 \mathrm{~h}$; 100- $\mu$ l samples were counted to determine the concentrations of bound and free ligand. 
A. bracteata lectin on SDS-PAGE and the absence of cysteine suggest the subunits are bound together by noncovalent interactions. Based on the intact molecular weight of 135,000 determined by gel filtration and the subunit molecular weights measured by SDS-PAGE, the native lectin probably occurs as a tetramer.

Amino terminal sequence data for the A. bracteata lectin provides further evidence for subunit heterogeneity. The variation in residues at positions one and five probably reflect distinet $N$-termini for the subunits. Resolution of these results will require isolation of individual subunits. Comparison of this sequence with the $N$ termini of other lectins reveals greatest homology with soybean agglutinin, there being identical amino acid residues in at least five of the first 10 positions (16). This is consistent with assignment of $A$. bracteata and Glycine max (soybean) to the same subtribe, Glycineae (17). The low content of sulfur containing amino acids found by this laboratory is also in accord with related legume lectins.

Hapten inhibition studies using the hog $\mathrm{A}+\mathrm{H}$ gastric mucin-A. bracteata lectin system confirm the essential monosaccharide specificity reported previously, based on inhibition of hemagglutination (2). The monosaccharide specificity was further examined using several derivatives of methyl $\alpha-N$-acetyl-D-galactosaminide. The lectin tolerates a number of alterations at the C2 position; methyl $2-N$-benzamido- $\alpha-\mathrm{D}-$ galactosaminide is as good an inhibitor of precipitation as methyl $N$-acetyl- $\alpha$-D-galactosaminide, and methyl 2-O-acetyl- $\alpha$-Dgalactoside is only slightly less inhibitory. It is interesting to note that substitution of the 2-N-acetyl moiety with a benzamido group enhances binding to lima bean lectin (18) but inhibits binding to $D$. biflorus lectin (8).

Precipitin inhibition studies also show the lectin to have a marked preference for the $\alpha$-anomeric form of methyl GalNAc. However, the $\alpha$ - and $\beta$-anomers of $p$-nitrophenyl $N$-acetylgalactosaminide and GalNAcl,6Gal have similar inhibition constants; 1 -[4-( $N$-acetyl- $\beta$-D-galactosaminyl)phenyl]-3-(2,2,6,6-tetramethylpiperi- din-1-oxyl-4-yl)-2-thiourea binds much more tightly than the $\alpha$-anomer in electron spin resonance studies (19). These results indicate that the lectin readily accommodates certain hydrophobic groups in the $\beta$ anomeric configuration. It is also apparent that the nitroxyl group sterically interferes with binding of the $\alpha$-anomer of the spin labeled glycoside. The lectin from $A$. bracteata does not exhibit the pronounced enhancement of binding of the $p$-nitrophenyl glycosides of GalNAc observed with Griffonia simplicifolia isolectin $\mathrm{I}_{-} \mathrm{A}_{4}(20)$.

Examination of the inhibitory potency of several disaccharides containing nonreducing GalNAc termini revealed the Forssman hapten (GalNAc $\alpha 1,3 \mathrm{GalNAc}$ ) to be the best inhibitor. It also appears that the $\alpha(1,2)$ and $\alpha(1,3)$ linkages are accommodated more readily than the $\alpha(1,6)$ linkage.

Isolation of the individual subunits has, so far, been unsuccessful. Anion-exchange chromatography and chromatofocussing in $8 \mathrm{M}$ urea have resulted in profiles containing mixtures of subunits. Dissociation by urea, even up to $10 \mathrm{M}$, with heating, does not appear to be complete. Detergents such as SDS and cholate are most effective. Separation by size has been unsuccessful due to the small differences in molecular weight. Further attempts to separate these subunits are in progress.

\section{REFERENCES}

1. MäKela, O., AND Mä́kela, P. (1956) Ann. Med. Exp. Biol. Fenn. 34, 403-404.

2. Blacik, L. J., Breen, M., Wennstein, H. G., SitTiG, R. A., AND Cole, M. (1978) Biochim. Biophys. Acta 538, 225-231.

3. Lowry, O. H., Rosebrough, N. J., FARR, A. L., and RaNDall, R. J. (1951) J. Biol. Chem. 193, $265-275$.

4. BREWER, J. M., AND ASHWORTH, R. B. (1969) $J$. Chem. Educ. 46, 41-45.

5. LAEMMLI, U. K. (1970) Nature (London) 227, 680685.

6. Roberts, D. D., ETZLER, M. E., AND Goldstein, I. J. (1982) J. Biol Chem. 257, 9198-9204.

7. RACUSSEN, D. (1979) Anal Biochem. 99, 474-476.

8. Hammarstróm, S., MurPhy, L. A., GoldSteIN, I. J., AND ETzLER, M. E. (1977) Biochemistry 16, 2750-2755. 
9. Kaifu, R., Plantefabor, L. C., and Goldstein, I. J. (1985) Carbohydr. Res. 140, 37-49.

10. So, L. L., AND GoLDSTEN, I. J. (1967) J. Biol Chem. 242, 1617-1622.

11. MAGE, R., AND DRAY, S. (1965) J. Immunol. 95, 525-535.

12. TARR, G. E. (1982) in IVth International Conference on Methods in Protein Sequencing (Elzinga, M., Ed.), pp. 223-232, Humana Press, Clifton, $\mathrm{NJ}$

13. KOOP, D. R., MORGAN, E. T., TARR, G. E., AND COON, M. J. (1982) J. Biol Chem. 257, 8472-8480.

14. Perini, F., AND Peters, B. P. (1982) Anal Biochem. 123, 357-363.

15. Carter, W. G., and Etzler, M. E. (1975) J. Biol. Chem. 250, 2756-2762.
16. Foriers, A., Wailmart, C., Sharon, N., and StrossberG, A. D. (1977) Biochem. Biophys. Res. Commun. 75, 980-986.

17. Hutchinson, J. (1964) The Genera of Flowering Plants, Vol. 1, Oxford Univ Press (Clarendon), Oxford.

18. ROBERTS, D. D., AND GOLDSTEIN, I. J. (1984) J. Biol. Chem. 259, 903-909.

19. Berliner, L. J., Musci, G., Maliarik, M., Plessas, N. R., AND GoLDSTEIN, I. J. (1986) Biochemistry 25, 4457-4461.

20. MurPhy, L. A., AND Goldstein, I. J. (1979) Biochemistry 18, 4999-5005.

21. ROBERTS, D. D., AND GOLDSTEIN, I. J. (1983) J. Biol Chem. 258, 13820-13824. 